\title{
Understanding the Behavioural Patterns of University Teachers Toward Using a Learning Management System
}

\author{
https://doi.org/10.3991/ijet.v16i14.22685 \\ Chien-Yuan Su $\left.{ }^{\bowtie}\right)$ \\ National University of Tainan, Tainan, Taiwan \\ bredysuegmail.com \\ Yu-Hang Li \\ Zhejiang Police College, Hangzhou, China \\ Cheng-Huan Chen \\ Asia University, Taichung, Taiwan
}

\begin{abstract}
Recent research has been very attentive to the examination of learners' behavioural patterns of using learning management systems (LMS), but these studies seldom address the diversity in the LMS usage behaviours of teachers. This study aimed to discover the behavioural patterns of university instructors regarding the use of an LMS by using sequential and clustering analysis techniques. The usage behaviours of 268 teachers at a public university in China were extracted from the Blackboard platform over the course of onesemester. These behaviours were classified according to five different LMS behavioural types: (1) course and content; (2) assignment; (3) communication and collaboration; (4) assessment; and (5) administration. The results indicated that the most frequent teachers' LMS usage behaviour was course and content followed by assessment and administration. The results of the sequential analysis indicated that most of the instructors are used to adopting communication and collaboration and assignment when they finish using course and content. In addition, three distinct usage behavioural pattern subgroups were named as teachers preferred assessment, teachers of regular use, and teachers of less use. Implications of these findings are discussed in the light of the university teachers' behavioural patterns toward using the LMS.
\end{abstract}

Keywords - Usage behaviour of teachers, learning management system, sequential analysis, cluster analysis, behavioural pattern mining

\section{Introduction}

Learning management systems (LMS), such as Blackboard or Moodle, have been adopted by higher education institutions worldwide and are considered to enhance new paradigms of both online and blended learning mode delivery [1]. These LMS platforms offer a variety of instructional services, which have the capabilities of supporting one or more specific teaching tasks [2]. For instance, teachers can upload 
teaching materials, prepare assessments or quizzes and learning assignments, and track or supervise students' online learning progress as a whole [3]. In the meantime, all usage behaviours of teachers are also recorded in LMS's database logs.

With the rapid advancement of data mining techniques, researchers can carry out user behavioural pattern mining to discover the valuable information extracted from large volumes of the LMS datasets [4-6]. For example, Munoz-Organero et al. [7] analyzed LMS usage behavioural patterns of 180 students at six different universities and concluded that their behavioural patterns regarding content reading, forum participation, and profile updating positively correlated with learning motivations and validated that these behavioural patterns can be used to predict motivation deficits. Lu \& Law [8] analyzed Moodle logs to investigate students' collaborative knowledge construction and peer assessment and found that students demonstrated more behavioural patterns, such as Wiki editing and grade and comment submission, rather than focusing on learning tasks and feedback of peers. Lust et al. [9] observed ways that undergraduates vary in their tool-use within an online course in LMS by cluster analysis, while Yin et al. [10] employed a progressive sequencing behavioural analysis to explore and infer graduate students' reading behavioural patterns in a web-based digital textbook learning system.

Most of these previous studies focused mainly on students' LMS behavioural analysis $[3,6,11,12]$. However, relatively little attention has been paid to investigating teachers' behaviours toward LMS usage [2] or to explore their LMS behavioural patterns in higher institutions. Using the data mining technique to help understand how university teachers use LMSs and their behavioural patterns could provide us with valuable information. This information could be used to enhance the instructional design and offer meaningful insights for researchers and educational institutions to develop appropriate instructional support. Accordingly, this study attempted to explore university teachers' LMS usage and examine their behavioural patterns toward LMS adoption. Both sequential and cluster analysis approaches were applied in this study to investigate the sequence of LMS usage exhibited by university teachers, explore the differential characteristics behind teachers' adoption behaviours by clustering in addition to seeking to examine the similarities and differences between different behavioural clusters. To achieve the purpose of the study, the four research questions were asked:

RQ1: What are the frequency and distribution of teachers' behaviours toward LMS usage?

RQ2: What are the overall sequential patterns toward the LMS usage displayed by teachers?

RQ3: How could distinct behavioural clusters be found based on similar teacher behavioural distributions toward LMS usage?

RQ4: What are the differences and similarities in sequential behavioural patterns among the distinct clusters? 


\section{$2 \quad$ Literature Review}

\subsection{Teachers' adoption of LMS}

Recently, many higher education institutions have established commercial (such as Blackboard) or open-source code (such as Moodle) learning management systems to assist teachers to carry out several specific instructional tasks. West et al. [13] pointed out that teachers utilizing either the LMS functionalities or toolset may depend upon individual levels (such as competencies or attitudes) or external conditions (such as instructional goals, institutional policies, or organizational need). In contrast, ComasQuinn [14] reported that teachers typically use LMS tools that mimic to their conventional teaching practices in a web-based setting. Several previous studies pointed out a similar usage behaviour regarding the use of LMS; in general, instructors demonstrated a higher distribution frequency for the arranging online teaching materials and less for communication with students and online assessment or collaborative learning [1]. Park et al. [15] analyzed 612 blended courses in a Korean University based on the activity data on LMS platform, and they found that a considerable variation existed among Korean university teachers despite demonstrating low LMS usage [16]. Four different teacher subtypes were summarized: inactive or immature; communication or collaboration; delivery or discussion, and sharing or submission. Chow et al. [1] adopted a Rasch analysis approach for the examination of teacher LMS usage behaviour logs by understanding the difference between teachers who have completed the training and those who have not. They found that teachers who attend LMS training workshops have higher levels of LMS operation compared to untrained teachers. In particular, trained teachers appeared to make comparatively more use of "grade centre" and of "assessment tool" but much less use of "content" in their teaching than did teachers who did not attend training.

\subsection{Behavioural patterns by sequence analysis}

Sequential pattern mining may be used to analyze frequently occurring events, such as those concerning time or other parameters. Briefly, given a collection of sequences, frequent subsequences can be identified in the sense that the frequency of such subsequences among data sequences exceeds user-specific minimum support [17]. For example, $\mathrm{Wu}$ et al. [18] used a sequential analysis to explore learning patterns, cognitive processing, and knowledge creation in an interactive concept mapping online discussion environment. Sun et al. [19] investigated students' learning behaviours and their learning achievements with different flow experiences in the educational game activity by using lag sequential analysis. They found that students in flow had more discussions with peers, and bored students repeatedly solved the problems until they succeeded in finding a solution. Students with anxiety were used to obtaining help from materials or peers but rarely showed the verifying information behaviour patterns after obtaining help. Hsu [20] employed a lag-sequential analysis to investigate 81 college students' behaviours toward employing three instant interactive 
mobile applications (LINE, PAL+, and SpeakUP!) for learning interactions in the flipped classroom. In this study, the teacher behavioural sequence is considered as the ordered set of teacher operation actions within the LMS. For example, teachers might upload teaching content and then set online assessment or perform to interact with students and then to admin or manage other teaching tasks by LMSs.

\subsection{Behavioural patterns by cluster analysis}

Cluster pattern analysis is a multivariate statistical technique for partitioning data in such a way that objects in given group characteristics are similar to each other and distinct from other groups [21]. It has been used in past research to find out subgroups of similar behavioural patterns [22,23]. For instance, Cerezo et al. [4] extracted Moodle logs and used k-means clustering to examine students' learning behavioural patterns with respect to three different types of contents: theoretical content; practical tasks; and discussion forums. Li and Tsai [24] used a two-step clustering approach to investigate students' behaviours of using LMS and found three different behavioural use patterns (consistent, slide intensive, and less) that correlated with motivation and learning performance. Codish et al. [25] proposed a behavioural pattern detection to discover, distinguish, and cluster students' usage patterns from LMS. They found five key behavioural patterns involving content contribution, content reading, badge collection, knowledge point collection, and social networking in students' behaviours while using LMSs. Apparently, although there are many cases that cluster students' behavioural patterns, less are concerned with teachers' adoption behaviours. Hence, we wanted to explore whether there are distinctive behavioural teacher subgroups that could be identified according to clustering their LMS adoption behaviours.

\section{Methodology}

The research context is a public university in an eastern Chinese coastal province. This university has used the Blackboard platform as a learning management system since 2017 to enhance instructional tasks. Instructors could upload course materials, set assignments, tests/quiz, or initiate online discussions to facilitate student interaction. The Blackboard database included the profile of registered teachers, function operation frequencies, and log-data related to the page visiting and other usage records of each teacher of a specific course. In this study, the range of datasets containing the teacher operation behaviour logs from August 2018 to January 2019 was used for behavioural analysis.

\subsection{Data extraction}

In the preliminary examination, registered information and usage behaviour records from approximately 689 instructors were stored in Blackboard. De-identification process was done to prevent possible ethical problems. A total of 405 teacher cases were removed because they were only registered but showed almost no use of LMS 
tools. Sixteen teacher cases were removed as outliers according to the standard operating ratio $(|Z|$ exceeds 3$)$ as described by Shiffler [26]. After deducting the appropriate sample of teachers and eliminating missing values, a sample of 268 teachers covering 34,561 usage behaviours were marked to be analysed in this study.

\subsection{Data coding}

In this study, we referred to a conceptual LMS framework proposed by Dabbagh \& Bannan-Ritland [27] in which four-categories are defined: (1) content creation and delivery tools; (2) collaborative and communication tools; (3) assessment tools; (4) administrative tools. We then readjusted teachers' operation categories regarding LMS usage, and coded behaviours of teachers' adoption of LMS into five different usage categories: (1) Course and Content (T1); (2) Assignment (T2); (3) Communication and Collaboration (T3); (4) Assessment (T4); and (5) Administration (T5), as shown in Table 1. In the process of data encoding, some easy-to-identify usage behaviours according to the system modules (such as grade centre, e-mail, course, etc.) in the LMS database are marked, while the unclear use operation records in the system logs are reconfirmed and analysed. To test the reliability of the data coding, all coded records were double-checked by two graduate students who majored in educational technology and received the same code-related training. The inter-coder reliability was $0.989(\mathrm{p}<.001)$, which demonstrated that the scheme coding was reasonable and credible.

Table 1. The coding scheme for teacher LMS behaviors

\begin{tabular}{|c|l|l|}
\hline Code & \multicolumn{1}{|c|}{ Tool category } & \multicolumn{1}{c|}{ Example } \\
\hline T1 & Course and Content & Create course content, announcements, syllabus, introduction, videos \\
\hline T2 & Assignment & $\begin{array}{l}\text { Create assignments, tasks, quizzes, exercises, tests, surveys, questions, } \\
\text { homework }\end{array}$ \\
\hline T3 & $\begin{array}{l}\text { Communication and } \\
\text { Collaboration }\end{array}$ & Use Ding talk, email, logs, discussion forums, blogs, Wiki, groups \\
\hline T4 & Assessment & $\begin{array}{l}\text { Use grade, grade indicator boards, grade centre, self-evaluation, and } \\
\text { mutual-evaluation }\end{array}$ \\
\hline T5 & Administration & $\begin{array}{l}\text { Use class management, data management, contacts, teaching calendar, } \\
\text { course report }\end{array}$ \\
\hline
\end{tabular}

\subsection{Analytical method used}

In this study, several statistical and data mining approaches were conducted to investigate distribution and changes in teachers' use of LMS: 
1. Frequency statistics were used to estimate the frequency and monthly distribution of teacher behaviours regarding the use of LMS.

2. The lag sequential analysis was used to examine whether the teachers' specific operational behaviour followed by another specific behaviour in time can reach statistical significance.

3. A two-stage cluster analysis was performed to explore distinct teacher subgroups by forming sub-groups of similar behavioural patterns. First, the optimum number of clustering teacher behavioural patterns based on the hierarchical clustering was calculated, and the resulting number of clusters was then used for the k-means clustering analysis.

4. A one-way analysis of variance (ANOVA) was conducted to investigate whether there were major variations in teacher behavioural patterns in LMS use across the distinct subgroups.

\section{Result}

\subsection{Behaviour frequency analysis}

The distribution trend diagram of the frequency regarding teachers' LMS usage behaviours is shown in Figure 1. There were 34,561 LMS adoption behaviours involving 268 teachers who were divided into five different behavioural types. The results showed that the primary behaviours of teachers' use of Blackboard consisted: (1) course and content (T1, 43.98\%); (2) assessment (T4, 22.63\%); (3) administration (T5, 14.05\%); (4) communication and collaboration (T3, 11.21\%); and (5) assignment (T2, 8.13\%).

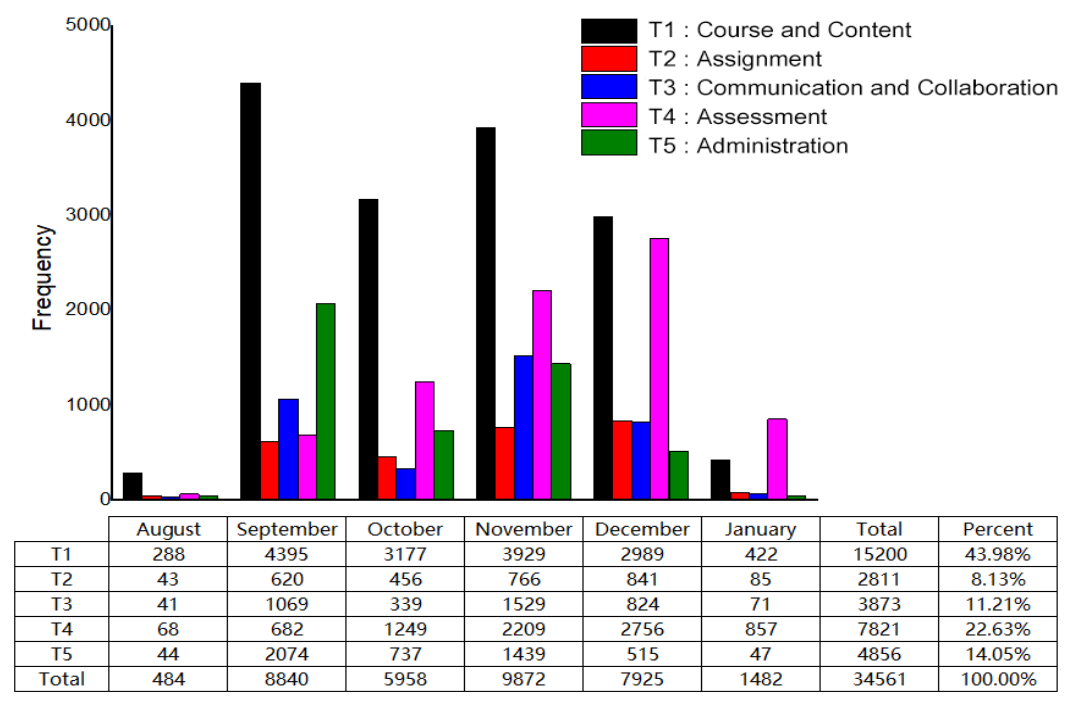

Fig. 1. Distribution of the descriptive frequency analysis of five behavioral types 


\subsection{Sequential analysis}

A sequential frequency transfer matrix [28] was conducted to examine the significance of each sequence for teachers' behaviour toward using Blackboard. As shown in Table 2, the rows represent the former teacher behaviours, and the columns represent the latter ones. To determine the significance level of the behavioural sequences, the $\mathrm{z}$ score of sequential analysis was used to explain whether there is a relevant association between behaviours. The z-scores of each sequence obtained were $>1.96(p<$ .05 ), thus representing a statistically significant behavioural sequence that occurred [28]. The sequence transition diagram is drawn in Figure 2 in which the arrow indicates the direction of a shift that reflects a significant sequence in which one behavioural category is followed by another one. The grayscale of the node represents the frequency percentage of one behaviour in all behaviours (nodes labelled with various shades of grey; the darker the colour of the node indicates more frequent use of this type of behavioural category). The direction of the arrow represents the order of the behavioural sequence, while the numbers on the line represent the significance (zscore) of behavioural transitions. It should be noted that continuous or repeated operational behaviours for each behavioural type (such as $\mathrm{T} 1 \rightarrow \mathrm{T} 1$ ) were ignored in this study.

Table 2. The adjusted residual for all teacher behaviors toward the use of Blackboard

\begin{tabular}{|c|c|c|c|c|c|}
\hline $\mathbf{Z}$ & T1 & T2 & T3 & T4 & T5 \\
\hline T1 & - & 12.49 & 16.41 & 1.01 & 11.33 \\
\hline T2 & 21.65 & - & -5.04 & -7.26 & -6.28 \\
\hline T3 & 23.88 & -5.39 & - & -5.84 & -3.97 \\
\hline T4 & 4.57 & -5.21 & -4.06 & - & -8.77 \\
\hline T5 & 20.32 & -5.39 & 3.06 & 1.01 & - \\
\hline
\end{tabular}

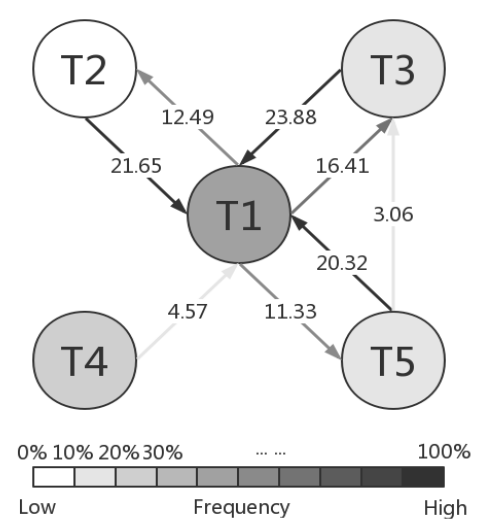

Fig. 2. Distribution of the descriptive frequency analysis of five behavioural types 
According to calculations, the results of eight significant sequences of teacher operations regarding Blackboard yielded a specific sequence in which $\mathrm{T} 1 \rightarrow \mathrm{T} 2, \mathrm{~T} 2 \rightarrow \mathrm{T} 1$, $\mathrm{T} 1 \rightarrow \mathrm{T} 3, \mathrm{~T} 3 \rightarrow \mathrm{T} 1, \mathrm{~T} 4 \rightarrow \mathrm{T} 1, \mathrm{~T} 1 \rightarrow \mathrm{T} 5, \mathrm{~T} 5 \rightarrow \mathrm{T} 1$, and $\mathrm{T} 5 \rightarrow \mathrm{T} 3$. There was an obvious behavioural transition between $\mathrm{T} 1$ and $\mathrm{T} 3(\mathrm{~T} 1 \rightarrow \mathrm{T} 3,16.41 ; \mathrm{T} 3 \rightarrow \mathrm{T} 1,23.88)$ followed by the behavioural transition between $\mathrm{T} 1$ and $\mathrm{T} 2(\mathrm{~T} 1 \rightarrow \mathrm{T} 2,12.49 ; \mathrm{T} 2 \rightarrow \mathrm{T} 1,21.65)$, indicating that the behavioural transition which using the communication and collaboration and assignment after using course and content reached statistical significance, and vice versa. Most of the teachers' operational behaviours revolved around course and content (T1). No matter what the behaviour change, the behaviour was transformed into other behavioural types through course and content. Unexpectedly, there was no obvious behavioural transition from course and content (T1) to assessment (T4) although the proportion of assessment was not too low (22.63\%). Another interesting finding is the transition from administration to communication and collaboration in which there were fewer connections between these two functions according to our coding scheme.

\subsection{Cluster analysis}

A two-stage cluster analysis was performed for teacher usage behavioural pattern classification after standardization with a vector of five behaviours. First, the optimal number and centroids of clusters were found by hierarchical clustering and then as inputs for conducting the k-means analysis. We refer to three criteria proposed by Gore et al. [29]: (1) meaningful group formation; parsimony examination; and an explanatory power $>50 \%$ of the explained variance for the five types of LMS usage behaviour. Accordingly, on the basis of these criteria, which require the most parsimony of classifications with apparent distinctions, the three-cluster solution was determined in the first stage, and three was the $\mathrm{k}$ value stated in the k-means analysis. A one-way ANOVA was performed to examine inter-cluster variations in behavioural patterns of LMS use among these clusters. Levene's test was used for all five LMS usage types, and the data violated homogeneity of variance assumption $(p<.05)$. The Welch F-ratio was therefore used to adjust for heterogeneity of within-group variance. In addition, the Games-Howell approach was used for post-hoc comparisons. The findings shown in Table 3 indicate that three subgroups differed significantly for each of five types: course and content, Welch's $F(2,18.67)=149.36, p<.001, \omega 2=.723$; assignment, Welch's $F(2,18.59)=12.19, p<.001, \omega 2=.219$; communication and collaboration, Welch's $F(2,19.83)=7.64, p<.001, \omega 2=.123$; assessment, Welch's $F(2,18.73)=60.64, p<.01, \omega 2=.724$; administration, Welch's $F(2,18.82)=20.12$, $p<.001, \omega 2=.267$. The three subgroups showed distinctive features in teacher usage behavioural pattern composition. The discriminant validation was conducted with the five behaviours of LMS adoption as the predictors and the three subgroups from the cluster analysis as the dependent variables. The discriminant function was successful in predicting group membership for $99.2 \%$ of the cases with accurate placement at $100.0 \%$ for cluster $1,98.1 \%$ for cluster 2 , and $99.5 \%$ for cluster 3 . The findings confirmed the three-cluster solution obtained from the cluster analysis. 
Table 3. ANOVA results and a comparison among the three clusters

\begin{tabular}{|c|c|c|c|c|c|c|}
\hline Code & $\begin{array}{c}\text { Total average } \\
\mathbf{n = 2 6 8}, \\
\boldsymbol{M}(\boldsymbol{S D})\end{array}$ & $\begin{array}{c}\text { Cluster 1 } \\
\mathbf{n = 9 ,} \\
\boldsymbol{M}(\boldsymbol{S D})\end{array}$ & $\begin{array}{c}\text { Cluster 2 } \\
\mathbf{n = 5 2} \\
\boldsymbol{M}(\boldsymbol{S} \boldsymbol{D})\end{array}$ & $\begin{array}{c}\text { Cluster 3 } \\
\mathbf{n = 2 0 7} \\
\boldsymbol{M}(\boldsymbol{S D})\end{array}$ & $\boldsymbol{F}$ & Partial $\boldsymbol{\eta}^{2}$ \\
\hline $\mathrm{T} 1$ & $\begin{array}{c}56.06 \\
(80.71)\end{array}$ & $\begin{array}{c}143.44 \\
(115.38)^{\mathrm{c}}\end{array}$ & $\begin{array}{c}188.06 \\
(69.21)^{\mathrm{c}}\end{array}$ & $\begin{array}{c}19.11 \\
(25.22)^{\mathrm{a}, \mathrm{b}}\end{array}$ & $149.36^{* *}$ & 0.723 \\
\hline $\mathrm{T} 2$ & $\begin{array}{c}41.26 \\
(29.70)\end{array}$ & $\begin{array}{c}41.33 \\
(52.04)\end{array}$ & $\begin{array}{c}36.00 \\
(50.78)^{\mathrm{c}}\end{array}$ & $\begin{array}{c}3.74 \\
(12.21)^{\mathrm{a}}\end{array}$ & $12.19^{* *}$ & 0.219 \\
\hline $\mathrm{T} 3$ & $\begin{array}{c}24.43 \\
(42.22)\end{array}$ & $\begin{array}{c}23.11 \\
(27.13)\end{array}$ & $\begin{array}{c}43.90 \\
(73.30)^{\mathrm{c}}\end{array}$ & $\begin{array}{c}6.65 \\
(25.84)^{\mathrm{a}}\end{array}$ & $7.64^{* *}$ & 0.123 \\
\hline $\mathrm{T} 4$ & $\begin{array}{c}29.18 \\
(83.42)\end{array}$ & $\begin{array}{c}401.89 \\
(110.50)^{\mathrm{b}, \mathrm{c}}\end{array}$ & $\begin{array}{c}44.58 \\
(69.35)^{\mathrm{a}, \mathrm{c}}\end{array}$ & $\begin{array}{c}9.11 \\
(28.65)^{\mathrm{a}, \mathrm{b}}\end{array}$ & $60.64^{* *}$ & 0.724 \\
\hline $\mathrm{T} 5$ & $\begin{array}{c}51.02 \\
(31.22)\end{array}$ & $\begin{array}{c}51.44 \\
(51.61)^{\mathrm{c}}\end{array}$ & $\begin{array}{c}46.96 \\
(44.24)^{\mathrm{c}}\end{array}$ & $\begin{array}{c}9.29 \\
(18.39)^{\mathrm{a}}\end{array}$ & $20.12^{* *}$ & 0.267 \\
\hline
\end{tabular}

Note. $* *$ means $p<.01$

a Statistically significant in comparison to cluster 1 .

b Statistically significant in comparison to cluster 2 .

c Statistically significant in comparison to cluster 3 .

\subsection{Characteristic of behavioural patterns among three sub-clusters}

A radar chart (see Figure 3) was drawn to display the identifiable distributions of the five types of use of LMS in which each spoke represents one of the quantitative variables via $\mathrm{z}$-score transformation. As a result, all of five usage types were on the same metric, and each would demonstrate equally to the formation of the clusters. The red dotted line was used to represent the average value for the LMS usage of the entire teacher sample, and the other solid lines were used to represent the specific clusters in each category of LMS usage. The behavioural features of each cluster were defined and described in the following section.

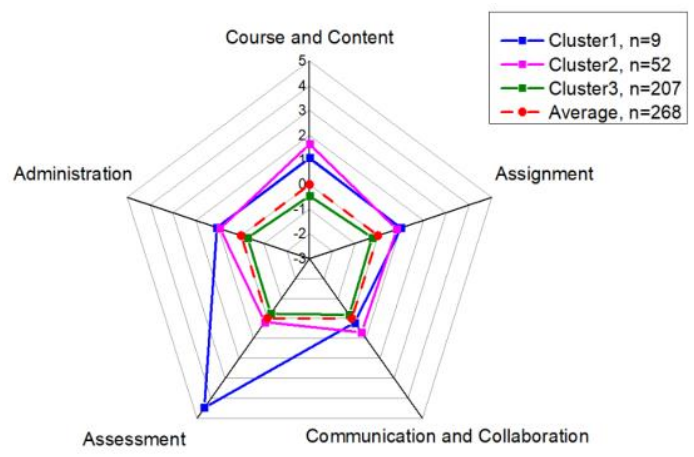

Fig. 3. Usage behavioural patterns of each cluster

Note. The red dashed line reflects the mean z-scores of the entire sample. Solid lines correspond to the mean z-scores among different clusters.

Cluster $1(n=9,3.36 \%)$ showed the smallest number of teachers among three groups and demonstrated the highest amount of usage involving assessment (401.89), 
assignment (41.33), and administration (51.44) compared to the other two clusters. All types toward LMS usage in this cluster are higher than the overall averages (143.44, 41.33, 23.11, 401.89, and 51.44 versus 56.06, 11.26, 14.43, 29.18, and 18.02, respectively). The usage rates in the category of assessment is much higher than in other categories. Thus, this cluster was labelled "teachers preferred assessment".

Cluster 2 included fifty-two teachers (19.40\% of the samples). This cluster had the highest scores with regard to the course and content (188.06) and communication and cooperation (43.90) compared to the other two clusters. Each score for LMS usage for each type, were greater than their respective overall averages $(19.11,3.74,6.65,9.11$, and 9.29 versus 56.06, 11.26, 14.43, 29.18, and 18.02, respectively). Thus, cluster 2 was labelled "teachers of regular use".

The third cluster was the largest within the three groups and contained two hundred and seven teachers (77.24\% of the samples). Teachers in this cluster had the lowest LMS usage with regard to the course and content (19.11), assignment (3.74), communication and cooperation (6.65), assessment (9.11), and administration (9.29) as compared to other two clusters. Thus, we labelled this group "teachers of less use".

\subsection{Comparis on of behavioural sequences among three sub-clusters}

A frequency transition table is shown in Table 4. The table indicates that the statistically significant behavioural sequences (the $\mathrm{z}$-score was determined to reflect the frequency of each behavioural type immediately after another behavioural type) regarding five LMS operation types among each cluster. The LMS types were converted into the behaviour-transfer diagrams (nodes and lines marked with different grey colours on which the black colour means a higher frequency) as presented in Figure 4. To further compare the behavioural diagram among three clusters, we found some similar behaviour sequences, for example, T1 $\leftrightarrow \mathrm{T} 2, \mathrm{~T} 3 \rightarrow \mathrm{T} 1$, and $\mathrm{T} 1 \rightarrow \mathrm{T} 5$ existed in all three groups. On the other hand, cluster 1 (teachers preferred assessment) was observed to have two obvious bi-directional behavioural sequence transitions in which one was between T1 and T2 (7.98 and 3.95), and the other was between T1 and T4 (5.71 and 8.74). Cluster 2 (teachers of regular use) was observed to have much more significant behavioural sequence transitions between T1 and T2 (10.96 and 10.68), T1 and T3 (13.44 and 20.62), and T1 and T5 (8.96 and 15.56), but there were no significant behaviour transitions between $\mathrm{T} 1$ and T4. Cluster 3 (teachers of less use) was observed to have two the most significant behavioural sequence transitions between $\mathrm{T} 1$ and T3 (10.58 and 12.19) and T1 and T5 (6.88 and 12.28). Moreover, there was some behavioural difference that exists between these three groups. Bidirectional sequences and (between $\mathrm{T} 1$ and $\mathrm{T} 3$ and $\mathrm{T} 1$ and $\mathrm{T} 5$ ) and a unidirectional sequence (T5 to T3) behaviours appeared in clusters 2 and 3 but only revealed a unidirectional sequence from $\mathrm{T} 3$ to $\mathrm{T} 1$ and $\mathrm{T} 1$ to T5 in cluster 1 . In other words, a bidirectional behaviour (T1 $\leftrightarrow \mathrm{T} 4$ ) occurred in cluster 1 , but only a unidirectional sequence (T4 to T1) or no behavioural sequence appeared in cluster 3 or 2 . 
Table 4. Frequency transition of the three sub-clusters

\begin{tabular}{|c|c|c|c|c|c|}
\hline $\mathbf{Z}$ & T1 & $\mathbf{T 2}$ & T3 & T4 & T5 \\
\hline \multicolumn{6}{|c|}{ Cluster 1} \\
\hline $\mathrm{T} 1$ & - & $10.96^{*}$ & $13.44^{*}$ & -0.24 & $8.96^{*}$ \\
\hline $\mathrm{T} 2$ & $19.68^{*}$ & - & -2.95 & -6.13 & -4.24 \\
\hline $\mathrm{T} 3$ & $20.62^{*}$ & -4.60 & - & -4.48 & -3.89 \\
\hline $\mathrm{T} 4$ & 0.47 & -5.07 & -4.48 & - & -7.31 \\
\hline T5 & $15.56^{*}$ & -4.36 & $2.71^{*}$ & -0.47 & - \\
\hline \multicolumn{6}{|c|}{ Cluster 2} \\
\hline $\mathrm{T} 1$ & - & $7.98^{*}$ & 1.17 & $5.71^{*}$ & $2.18^{*}$ \\
\hline $\mathrm{T} 2$ & $3.95^{*}$ & - & -2.36 & -0.09 & -3.37 \\
\hline $\mathrm{T} 3$ & $4.45^{*}$ & -2.11 & - & -2.87 & -3.12 \\
\hline $\mathrm{T} 4$ & $8.74^{*}$ & 1.68 & -1.10 & - & -1.10 \\
\hline T5 & 1.93 & -1.60 & -1.86 & $2.43^{*}$ & - \\
\hline \multicolumn{6}{|c|}{ Cluster 3} \\
\hline $\mathrm{T} 1$ & - & $2.54^{*}$ & $10.58^{*}$ & -1.49 & 6.88* \\
\hline $\mathrm{T} 2$ & $9.78^{*}$ & - & -3.58 & -4.70 & -3.42 \\
\hline $\mathrm{T} 3$ & $12.19^{*}$ & -2.13 & - & -2.61 & 0.12 \\
\hline $\mathrm{T} 4$ & $2.05^{*}$ & -3.58 & -0.52 & - & -5.19 \\
\hline $\mathrm{T} 5$ & $14.28^{*}$ & -2.77 & $3.02^{*}$ & 0.93 & - \\
\hline
\end{tabular}

$* \mathrm{p}<.05$

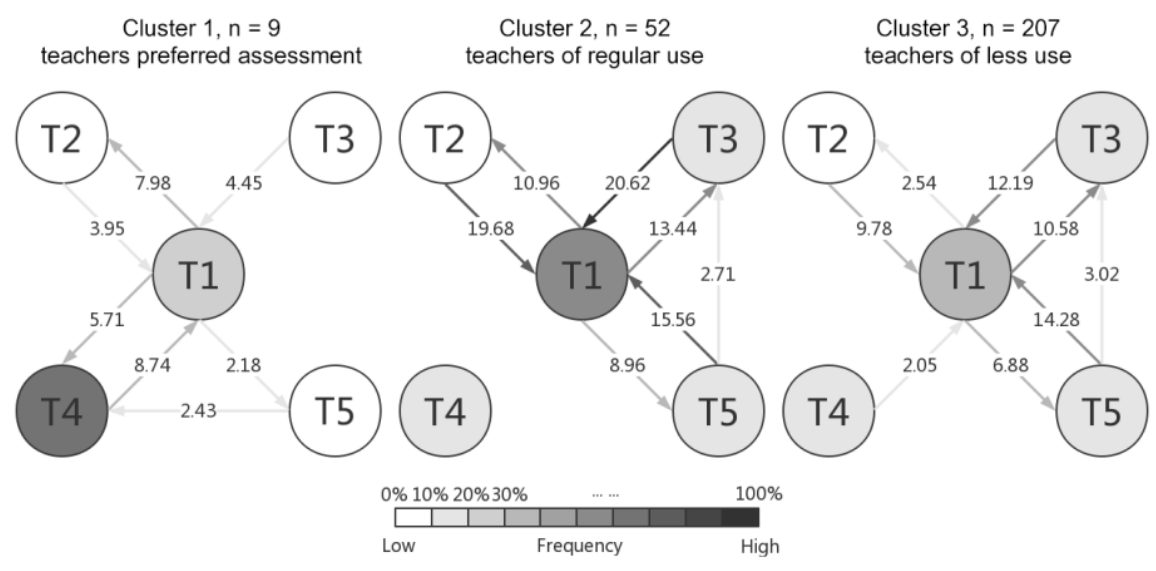

Fig. 4. Behavioural transfer diagram of the behavioural sequence patterns among different teacher clusters

\section{Discussion}

In this semester-long observational study, we conducted a sequential and cluster analysis in order to understand teacher behavioural patterns toward using an LMS.

To answer RQ1. It was observed that teachers had the highest usage in course and content and lowest usage in assignment. The results revealed that the LMS usage 
behaviour of university teachers were primarily confined to creating or uploading instructional materials or course content for students to access or download. This finding is consistent with prior studies involving LMS utilization in which teachers mostly focused on content editing or materials production compared to others $[1,30]$. Macfadyen and Dawson [31] also pointed out that teachers usually had a higher percentage with respect to the use of content and announcements or assessment (only quizzes) LMS tools because they are given less effort or time to operate these tools. Chow et al. [2] also argued that teachers were generally used to use LMS tools such as Content, Announcement, and Discussion Board for their instruction and less likely to use tools such as Wikis, 'Message, Collaboration, Journal and Blog, and Tasks. Additionally, some researchers mentioned that when instructors prepare the teaching content in the LMS platforms, they almost only use basic LMS functions, for example, posting their syllabuses and uploading lecture notes [32]. Moreover, viewing the frequency changes, the teacher assessment behaviour tended to increase month by month. The reason may be due to the proximity to the semester's final exam, which increases the number of times teachers used assessment. However, despite the advantages brought about by the LMS use that could promote e-instruction, the overall proportions of LMS usage are still low among teacher participants in this study. The reason for this result may be teachers' attitude toward using LMS [33] in which most teachers may consider using LMS for teaching as a supplementary or alternative to classroom teaching or due to barriers, such as fear and concerns when adopting LMSs [34].

For RQ2. To observe teacher behavioural sequence changes among five different Blackboard usage types (see arrow directions), a significant two-way behavioural sequence pattern between course and content and assignment ( $1 \leftrightarrow \leftrightarrow \mathrm{T} 2)$, course and content and communication and collaboration ( $\mathrm{T} 1 \leftrightarrow \mathrm{T} 3)$, or course and content and administration ( $\mathrm{T} 1 \leftrightarrow \mathrm{T} 5)$ was noted, while a unidirectional sequence pattern from assessment to course and content (T4 $\rightarrow \mathrm{T} 1)$ and from administration to communication and collaboration (T5 $\rightarrow \mathrm{T} 3$ ) existed. It is thought that teachers tend to use the Blackboard platform to deal with teaching materials than carry out different tasks, such as assignments, communication and collaboration, and administration, and vice versa. In particular, by comparing the frequency of behavioural sequence, the most frequent sequence behaviour was from communication and collaboration (T3) to course and content (T1) followed by assignment (T2) to course and content (T1). It is worth noting that teacher assessment (T4) behaviour appeared at a higher frequency than assignment, communication and collaboration, and administration but only showed a lower one-way behavioural transition (assessment to course and content [T4 $\rightarrow \mathrm{T} 1])$. We speculated that teachers were used to performing assessments as the end of their Blackboard adoption or used assessment individually in their teaching process. Besides, we found that some tedious, repetitive operation behaviours appeared in some specific LMS functional modules. This finding may imply that teachers may not have been quite familiar with the use of the Blackboard toolsets when they performed some teaching tasks. This result is consistent with results from Chow et al. [2], indicating that trained teachers versus untrained teachers represented more behaviours in operating various LMS functions. The research of [35] also showed low participation 
of usage in LMS for Taiwanese university professors because they might have been fearful of technology or had less time.

For RQ3. From a more detailed perspective by cluster analysis, we could understand the behavioural usage distributions for different teacher sub-clusters and could identify the unique behavioural characteristics of each cluster. Three distinct clusters with the different behavioural distribution were defined as "teachers preferred assessment," "teachers of regular use," and "teachers of less use." A few teachers belonged to the "teachers preferred assessment" cluster, and these teachers had higher levels of five behavioural usage types than the average in all of these and demonstrated the highest proportion of assessment. The behavioural pattern of this cluster is in line with a previous investigation of 800 instructors in 35 institutions using the Blackboard platform, indicating few teachers use the LMS tools to assess students or improve the community [36]. The "teachers of regular use" cluster showed regular LMS usage toward Blackboard and had a higher usage frequency than the average level. Moreover, they showed the highest frequency in course and content and communication and collaboration among the three clusters. The cluster "teachers of less use" covered the majority of teachers with the lowest LMS usage among three clusters. Our findings were line with Schoonenboom's research [1], speculating that most teachers may not be familiar with the use of LMS for instructional tasks. Zanjani et al. [37] also noted that the teachers' awareness of the LMS functions might affect their involvement in the use of the LMSs. Despite use or adoption of LMS, the use may be affected by many individual factors, such as instructors' attitudes, beliefs, teaching philosophies and habits, capabilities, or participation in activities in addition to preparing appropriate teaching tasks and assessment procedures [38].

For RQ4. Three similar LMS usage behavioural sequences among three clusters occurred, which were between course and content and assignment (T1 $\leftrightarrow \mathrm{T} 2)$, communication and collaboration to course and content $(\mathrm{T} 3 \rightarrow \mathrm{T} 1)$, and course and content to administration $(\mathrm{T} 1 \rightarrow \mathrm{T} 5)$. This finding indicated that teachers in three groups tended to repeatedly prepare assignment immediately after they conducted course and content, or they carried out course and content after performing assignment. Teachers in the three groups also tended to repeatedly perform communication and collaboration (T3) to course and content (T1) and course and content (T1) to administration (T5). The group "teachers of regular use" exhibited the most significant usage behavioural sequence from $\mathrm{T} 3$ to $\mathrm{T} 1$ followed by $\mathrm{T} 1$ to $\mathrm{T} 2$. This finding indicates that teachers may tend to perform course and content after prepared communication and collaboration, or to carry out assignment after dealing with course and content when they use Blackboard. For the cluster "teachers preferred assessment," they demonstrated obvious LMS usage sequence behaviours focused on between course and content and assessment (T1↔T4). Teachers in this cluster might be more used to preparing the assessment after finishing to perform course and content and vice versa. The group "teachers of less use" showed the more common sequence behaviour that is course and content $\leftrightarrow$ assignment $(\mathrm{T} 1 \leftrightarrow \mathrm{T} 2)$, course and content $\leftrightarrow$ communication and collaboration (T1 $\leftrightarrow \mathrm{T} 3$ ), and course and content $\leftrightarrow$ administration (T1 $\leftrightarrow \mathrm{T} 5)$. Interestingly, a particular phenomenon is that the usage rate of assessment (tests, quizzes) is high, but there is no sequence behaviour connected with. In addition, administra- 
tion to communication and collaboration $(\mathrm{T} 5 \rightarrow \mathrm{T} 3)$ appeared only in the "teachers of regular use" and the "teachers of less frequent use" groups, demonstrating that these teachers display the sequencing behaviour significance of using administration to communication and collaboration while the "teachers of less frequent use" does not. Moreover, the group "teachers of less use" showed the highest behavioural sequence in which T5 to T1(14.28) was followed by T3 to T1 (12.19). This finding indicates that teachers in this cluster may have a higher tendency to operate course and content after finishing administration or communication and collaboration.

\section{Conclusion}

This study used sequential and cluster analyses in one institution of higher education to explore university teachers' behavioural patterns regarding the adoption and use of Blackboard. The results showed that a majority of teachers prefer to adopt content and assessment when they used Blackboard as a learning management system in addition to demonstrating a higher behavioural transition between course and content and assignment or course and content and communication and collaboration. Most teachers could only use the assessment functions to conduct assessment tasks but rarely demonstrated other operational behaviours when using LMSs. Moreover, the three diverse teacher clusters were identified via two-stage clustering.

Overall, this study could enrich the empirical understanding of university teachers' adoption behaviours of using an LMS and their behavioural patterns in higher education. Although some interesting findings are presented, there are several limitations to this study. For instance, the study participants were from one participating university, which could affect the representativeness of the sample and results generalization. Future research could further elaborate on these preliminary results by conducting a longitudinal study with more and different universities to examine teachers' behavioural patterns under varied mining analytical methods. Besides, this study only explored teacher behavioural patterns from the perspective of external behaviour and did not probe the underlying psychological factors which shape these behaviours. Teachers exhibited different LMS usage behaviours that might link to individual differences, or dominated by instructional purposes, preferences, and even information and communication technology (ICT) perceptions. Future research can explore the factors described above to gain a more comprehensive understanding of teachers' behaviours of adopting LMSs.

\section{$7 \quad$ References}

[1] Schoonenboom, J. (2014). Using an adapted, task-level technology acceptance model to ex plain why instructors in higher education intend to use some learning management system t ools more than others. Computers \& Education, 71, 247-256. https://doi.org/10.1016/j.com pedu.2013.09.016 
[2] Chow, J., Tse, A., \& Armatas, C. (2018). Comparing trained and untrained teachers on thei $\mathrm{r}$ use of LMS tools using the Rasch analysis. Computers \& Education, 123, 124-137. https://doi.org/10.1016/j.compedu.2018.04.009

[3] Watson, W. R., Watson, S. L., \& Lee Watson, S. (2007). An argument for clarity: What are learning management systems, what are they not, and what should they become? TechTre nds, 51(2), 28-34. https://doi.org/10.1007/s11528-007-0023-y

[4] Cerezo, R., Sánchez Santillán, M., Paule Ruiz, M. P., \& Núñez, J. C. (2016). Students’ LM $\mathrm{S}$ interaction patterns and their relationship with achievement: A case study in higher educ ation. Computers \& Education, 96, 42-54. https://doi.org/10.1016/j.compedu.2016.02.006

[5] Koh, J. H. L., \& Kan, R. Y. P. (2020). Perceptions of learning management system quality, satisfaction, and usage: Differences among students of the arts. Australasian Journal of Ed ucational Technology, 36(3), 26-40. https://doi.org/10.14742/ajet.5187

[6] Zhang, Y., Ghandour, A., \& Shestak, V. (2020). Using learning analytics to predict student s' performance in moodle LMS. International Journal of Emerging Technologies in Learni ng (iJET), 15(20), 102-115. https://doi.org/10.3991/ijet.v15i20.15915

[7] Munoz Organero, M., Munoz Merino, P. J., \& Kloos, C. D. (2010). Student behaviour and interaction patterns with an LMS as motivation predictors in e-learning settings. IEEE Tran sactions on Education, 53(3), 463-470. https://doi.org/10.1109/te.2009.2027433

[8] Lu, J., \& Law, N. W. Y. (2012). Understanding collaborative learning behaviour from Moo dle log data. Interactive Learning Environments, 20(5), 451-466. https://doi.org/10.1080/1 $\underline{0494820.2010 .529817}$

[9] Lust, G., Elen, J., \& Clarebout, G. (2013). Regulation of tool-use within a blended course: Student differences and performance effects. Computers \& Education, 60(1), 385-395. https://doi.org/10.1016/i.compedu.2012.09.001

[10] Yin, C. J., Uosaki, N., Chu, H. C., Hwang, G. J., Hwang, J. J., Hatono, I., \& Tabata, Y. (20 17). Learning behavioural pattern analysis based on students' logs in reading digital books. In Chen, W. et al. (Eds.). The 25th International Conference on Computers in Education ( pp. 549-557), Asia-Pacific Society for Computers in Education.

[11] Cantabella, M., Martínez España, R., Ayuso, B., Yáñez, J. A., \& Muñoz, A. (2019). Analy sis of student behaviour in learning management systems through a big data framework. Fu ture Generation Computer Systems, 90, 262-272. https://doi.org/https://doi.org/10.1016/j.f uture.2018.08.003

[12] Alturise, F. (2020). Evaluation of blackboard learning management system for full online c ourses in western branch colleges of Qassim University. International Journal of Emerging Technologies in Learning (iJET), 15(15), 33-51. https://doi.org/10.3991/ijet.v15i15.14199

[13] West, R. E., Waddoups, G., \& Graham, C. R. (2007). Understanding the experiences of ins tructors as they adopt a course management system. Educational Technology Research and Development, 55(1), 1-26. https://doi.org/10.1007/s11423-006-9018-1

[14] Comas Quinn, A. (2011). Learning to teach online or learning to become an online teacher: An exploration of teachers' experiences in a blended learning course. ReCALL, 23(3), 21 8-232. https://doi.org/10.1017/S0958344011000152

[15] Park, Y., Yu, J. H., \& Jo, I. H. (2016). Clustering blended learning courses by online behav iour data: A case study in a Korean higher education institute. Internet \& Higher Education , 29, 1-11. https://doi.org/10.1016/j.iheduc.2015.11.001

[16] Park, Y., \& Jo, I. H. (2017). Using log variables in a learning management system to evalu ate learning activity using the lens of activity theory. Assessment \& Evaluation in Higher E ducation, 42(4), 531-547. https://doi.org/10.1080/02602938.2016.1158236

[17] Srikant, R., \& Agrawal, R. (1996). Mining sequential patterns: Generalizations and perfor mance improvements. In: Apers P., Bouzeghoub M., Gardarin G. (Eds.), Lecture Notes in 
Computer Science: vol. 1057. Advances in Extending Database Technology (pp.1-17). Spr inger.

[18] Wu, S. Y., Chen, S. Y., \& Hou, H. T. (2016). Exploring the interactive patterns of concept map-based online discussion: A sequential analysis of users' operations, cognitive processi ng, and knowledge construction. Interactive Learning Environments, 24(8), 1778-1794. https://doi.org/10.1080/10494820.2015.1057740

[19] Sun, J. C. Y., Kuo, C. Y., Hou, H. T., \& Lin, Y. Y. (2017). Exploring learners' sequential behavioural patterns, flow experience, and learning performance in an anti-phishing educat ional game. Educational Technology \& Society, 20(1), 45-60. Retrieved from https://www.jstor.org/stable/pdf/jeductechsoci.20.1.45.pdf

[20] Hsu, T. C. (2019). The different effects of daily-life instant response social media and an e ducational feedback system on flipped learning: from the evidence of behavioural analysis. Interactive Learning Environments, 1-20. https://doi.org/10.1080/10494820.2019.169235 $\underline{8}$

[21] Lee, K., Kim, J., Kwon, K. H., Han, Y., \& Kim, S. (2008). DDoS attack detection method using cluster analysis. Expert Systems with Applications, 34(3), 1659-1665. https://doi.org /10.1016/j.eswa.2007.01.040

[22] Asif, R., Merceron, A., Ali, S. A., \& Haider, N. G. (2017). Analyzing undergraduate stude nts' performance using educational data mining. Computers \& Education, 113, 177-194. https://doi.org/10.1016/j.compedu.2017.05.007

[23] Rakic, S., Tasic, N., Marjanovic, U., Softic, S., Lüftenegger, E., \& Turcin, I. (2020). Stude nt performance on an e-learning platform: Mixed method approach. International Journal o f Emerging Technologies in Learning (iJET), 15(2), 187-203. https://doi.org/10.3991/ijet.v $\underline{15 \mathrm{i} 02.11646}$

[24] Li, L. Y., \& Tsai, C. C. (2017). Accessing online learning material: Quantitative behaviour patterns and their effects on motivation and learning performance. Computers \& Educatio n, 114, 286-297. https://doi.org/10.1016/j.compedu.2017.07.007

[25] Codish, D., Rabin, E., \&Ravid, G. (2019). User behaviour pattern detection in unstructured processes-a learning management system case study. Interactive Learning Environments, 27(5-6), 699-725. https://doi.org/10.1080/10494820.2019.1610456

[26] Shiffler, R. E. (1988). Maximum z scores and outliers. The American Statistician, 42(1), 7 9-80. https://doi.org/10.1080/00031305.1988.10475530

[27] Dabbagh, N., \& Bannan-Ritland, B. (2005). Online learning: Concepts, strategies, and appl ication. Pearson Prentice Hall.

[28] Bakeman, R., \& Gottman, J. (1997). Observing interaction: An introduction to sequential a nalysis (2nd ed.). Cambridge University Press.

[29] Gore, P. A. J. (2000). Cluster analysis. In H. E. A. Tinsley \& S. D. Brown (Ed.), Handbook of applied multivariate statistics and mathematical modeling (pp. 297-321). Academic Pre ss.

[30] Garrote Jurado, R., Pettersson, T., Regueiro Gomez, A., \& Scheja, M. (2014, November 24 -28). Classification of the features in learning management systems [Conference presentati on]. The XVII Scientific Convention on Engineering and Architecture, Havana, Cuba. http: //www.cciacuba.com/

[31] Macfadyen, L. P., \& Dawson, S. (2012). Numbers are not enough. Why e-learning analytic $\mathrm{s}$ failed to inform an institutional strategic plan. Journal of Educational Technology \& Soci ety, 15(3), 149-163.

[32] Dahlstrom, E., Brooks, D. C., \& Bichsel, J. (2014). The current ecosystem of learning man agement systems in higher education: Student, faculty, and IT perspectives (Research Repo 
rt No. 1414). EDUCAUSE Center for Analysis and Research. https://library.educause.edu/ -/media/files/library/2014/9/ers1414-pdf.pdf

[33] Bervell, B., \& Umar, I. N. (2017). A decade of LMS acceptance and adoption research in S ub-Sahara African higher education: A systematic review of models, methodologies, milest ones and main challenges. Eurasia Journal of Mathematics, Science and Technology Educa tion, 13(11), 7269-7286. https://doi.org/10.12973/ejmste/79444

[34] Sinclair, J., \& Aho, A. M. (2018). Experts on super innovators: Understanding staff adopti on of learning management systems. Higher Education Research \& Development, 37(1), 1 58-172. https://doi.org/10.1080/07294360.2017.1342609

[35] Yueh, H. P., \& Hsu, S. (2008). Designing a learning management system to support instruc tion. Communications of the ACM, 51(4), 59-63. https://doi.org/10.1145/1330311.133032 $\underline{4}$

[36] Woods, R., Baker, J. D., \& Hopper, D. (2004). Hybrid structures: Faculty use and percepti on of web-based courseware as a supplement to face-to-face instruction. The Internet and Higher Education, 7(4), 281-297. https://doi.org/10.1016/j.iheduc.2004.09.002

[37] Zanjani, N., Edwards, S. L., Nykvist, S., \& Geva, S. (2017). The important elements of L MS design that affect user engagement with e-learning tools within LMSs in the higher ed ucation sector. Australasian Journal of Educational Technology, 33(1), 19-31. https://doi.o rg/10.14742/ajet.2938

[38] Zanjani, N., Edwards, S. L., Nykvist, S., \& Geva, S. (2016). LMS acceptance: The instruct or role. Asia-Pacific Education Researcher, 25(4), 519-526. https://doi.org/10.1007/s40299 $\underline{-016-0277-2}$

\section{Authors}

Chien-Yuan Su is an assistant professor in the Department of Education, National University of Tainan, Taiwan. He earned his Ph.D. from National Cheng Kung University, Taiwan. His research interests include e-learning and educational technology.

Yu-hang Li is an executive officer in the Teaching Affairs Office of Zhejiang Police College in China. He received his master's degree from Zhejiang University in China. His research interests include educational technology.

Cheng-Huan Chen is an assistant professor in the Department of M-Commerce and Multimedia Applications at Asia University, Taichung, Taiwan. He received his Ph.D. and master's degrees from National Taiwan Normal University. His research interests include technology-enhanced learning, computer-supported collaborative learning, and educational technology.

Article submitted 2021-03-16. Resubmitted 2021-04-28. Final acceptance 2021-04-30. Final version published as submitted by the authors. 